\title{
Mental health Apps to address inequitable access to care in specific regions of the global North and South: A scoping review
}

\author{
Review \\ Raneeshan Rasendran ${ }^{1}$, Farah Ahmad ${ }^{1}$ \\ ${ }^{1}$ School of Health Policy and Management, York University, Toronto, Ontario, Canada \\ Corresponding author: F. Ahmad (farahmad@yorku.ca)
}

\section{ABSTRACT}

Introduction: There is a recent growth in the development of mental health applications (MHApps) to reduce stigma, improve knowledge and facilitate access to care especially for common mood disorders. Yet, it remains unclear whether such interventions can address the access to care gap equitably in the global North and South. Gaining such an understanding could yield valuable insights for mental health innovations at large and specifically amidst the heightened mental health risks of the COVID-19 pandemic. Methods: Using Arksey and O'Malley's method, a scoping review was conducted on academic and grey literature published between 2015 and 2019. India and China were selected as exemplars of the global South, and Canada and the US for the global North. The literature was synthesized through thematic analysis, employing a social determinants of health lens. Results: A total of 18 articles were selected for full-text review. Results reveal that MHAPPs for depression and anxiety are efficacious in improving symptoms across the examined regions. Mental health outcome scores improved in 13 studies. Yet, a lack of public awareness in the global North, together with logistical barriers that include mental health stigma/discrimination, financial and social challenges, and cultural barriers to self-care in the global South, all inhibit the uptake of MHApps. Conclusion: Awareness of MHAPPs and logistical barriers must be addressed to make MHAPPs more accessible. Policy makers should be cautious in implementing MHAppss in disadvantaged communities given several challenges. A broader policy level emphasis is needed to address the logistical capabilities and cultural sensitivity of MHAppss. The findings are also discussed in relation to the digital innovations for mental health in the pandemic. Given the focus of the presented review on specific regions, the transferability of findings warrant caution.

\section{KEYWORDS}

Access, eHealth, Global Mental Health, mHealth, Mobile Health

\section{INTRODUCTION}

The incidence of common mood disorders such as depression and anxiety are steadily increasing worldwide. For example, the World Health Organization estimates that over 264 million people are diagnosed or living with depression which continues to be a major cause of morbidity and mortality globally (World Health Organization, 2020). Experts project that by 2030 depressive disorders will rank first in the developed countries and second in middle- and low-income regions in relation to lost disability-adjusted-life-years (Mathers \& Loncar, 2006). Although evidence-based treatments and care

IHTP, 1(2), 176-190, 2021 programs exist for conditions like major depression and generalized anxiety, the unmet care needs for common mood disorders are high. Approximately, $75 \%$ to $85 \%$ of individuals living with mental health disorders in middle- and low-income countries receive minimal treatment (Wang et al, 2007). This number has further increased following the onset of the COVID-19 pandemic (Salari et al., 2020), causing policy makers, healthcare providers, and researchers in high- and low-income countries (also known as the global North and South, respectively) to call for increased access to mental health care (Dados \& Connell, 2012). 
Online mental health interventions delivered via digital devices or mental health apps (MHApps) can serve to reduce the gaps in access to mental health care. Evidence from various developed countries demonstrates the effectiveness of such interventions. For example, Andersson and Cuijpers (2009) reported a mean effect size of 0.41 in their meta-analysis of 12 studies that used computer/Internet-based interventions for depression. Likewise, Andrews et al. (2010) reported mean effect sizes of 0.78 for depression, 1.12 for generalized anxiety, 0.92 for social phobia and 0.83 for panic disorder in their review of 22 such studies. Despite the evidence on effectiveness, access by the community requires ongoing efforts due to the digital divide (Poushter, 2016). Nonetheless, proponents of MHApps argue for their potential in the global South as well (Fairburn \& Patel, 2017).

Scholars present several reasons to consider MHApps in the global South as a viable option in closing the mental health access gap. Firstly, there is a steady increase in the use of Internet and the emergence of affordable smartphones in the region (Poushter et al., 2018, p. 4). In 2013, for example, a median of $45 \%$ across 21 emerging and developing countries reported using the Internet at least occasionally or owning a smartphone, and the figure rose to 54\% just two years later (Poushter, 2016). Further, MHApps could reduce the challenges posed by the low number of mental health professionals for face-to-face therapy in many of the countries in the global South. For example, in a large country like India, the number of psychiatrists, nurses, psychologists and social workers for every 100,000 residents is estimated as $0.3,0.12,0.07$ and 0.07 (WHO India, 2019). MHApps could also be used by people remotely, with or without therapist, reducing travel time and cost (Donker, 2009; Christensen, 2010), allowing access to people residing in remote areas or with transportation challenges. Moreover, the burden of human suffering and economic impact is huge in the global South because $80 \%$ of all people diagnosed with a mental health disorder reside there (Rathod et al., 2017). This prevalence of compromised mental health in the global South is linked to population density. For example, 1.37 billion people reside in India and represent $17.8 \%$ of the world population (Worldometers, 2019). It is also linked to structural socioeconomic inequities, which have been associated by some scholars to the growing global hold of neoliberalism that supports reduction in government's social spending including healthcare while encouraging privatization and deregulation (Lund et al., 2010, p. 16). Thus, addressing mental health in innovative and equitable ways is important to reduce people's suffering and to contribute in the economic prosperity of nations.

Whether MHApps facilitate use, uptake, and adherence to mental health care in the global South and global North is an important area to examine. The digital divide in the North still exists (Poushter, 2016) while MHApps is an emergent area for the global South. For example, in 2015 Arjadi et al. conducted a systematic review of quantitative studies in the lowand middle-income countries and only three randomized controlled trials were found on the effectiveness - the specific mental health conditions addressed by the MHApps and access to care remained unexamined. With the aim to enhance scholarly understanding, our team conducted a scoping review using Arksey and O'Malley's (2005) framework for literature review. For specificity of the review and ensuing recommendations, Canada and the United States were chosen to represent the global North, while China (including Hong Kong and Taiwan) and India were selected to represent the global South. The selection of these countries was informed by their Gross Domestic Product (The World Bank, 2019). India and China were selected as emerging economies while they also represent $36.17 \%$ of the worlds' population. New insights for these regions in the global South could mean informing mental health programs for millions of people. Canada and the USA were selected based on their economic similarity and the rapid development of MHApps in both.

\section{RESEARCH QUESTIONS}

The specific research questions for both global South and North were:

1) Are MHApps effective/efficacious?

2) What is the impact of MHApps on access (use, uptake, adherence) to mental health services?

3) What are the facilitators and barriers to using MHApps? 
The findings can be used to inform policy, practice, and research in global mental health care by identifying areas of success and gaps for future initiatives. This area is particularly relevant given the growing mental health impact of the COVID-19 pandemic. The social distancing policies in place to curtail the spread of the virus have led to a loss of routines, feelings of frustration, loneliness, hopelessness, and symptoms of anxiety and depression (Salari et al., 2020).

\section{METHODS}

The framework proposed by Arksey and O'Malley (2005) was used due to the broad nature of the research questions being asked. The scoping approach allows inclusion of both qualitative and quantitative research and multiple sources of information. Reviewing a broad body of published literature is necessary to make recommendations for a wider audience. The five steps employed for the scoping study, were: (1) developing a research question, (2) searching literature by using inclusion and exclusion criteria, (3) selecting articles, (4) charting of data extracted from included articles, and (5) collating, summarizing, and reporting the findings.

To better conceptualize access to mental health care, the review was guided by foci of use, uptake and adherence to MHApps. The use of MHApps was assessed by reviewing study participant demographic and whether results included diverse populations. The uptake of MHApps was examined by reviewing duration of use by participants. The adherence of MHApps was assessed by reviewing participants who used the intervention for the full duration of study.

The search of literature in the reported study followed a systematic and rigorous approach (Figure 1). The electronic databases of MEDLINE, PsycINFO, Sociological Abstracts and Social Science Abstracts were searched for the years between 2015 and June 15th, 2019. Drawing from Arjadi et al.'s 2015 systematic review of online interventions for mental health, the keywords included 'online,' 'web,' 'internet,' 'internet-based,' 'app,' 'apps,' 'application*,' 'tablet*,' 'ipad,' 'depression,' and 'anxiety.' Nonetheless, our review is distinct from that of Arjadi et al.'s in that we included countries from both the global North and South, and both quantitative and qualitative studies. The country names included in the searches were Canada, US, India, China, Hong Kong and Taiwan. The Journal of Medical Internet Research was independently evaluated for relevant articles. Additionally, grey literature was searched via Google and Google Scholar using the previously identified key terms. The first six pages were reviewed as there was a low yield of relevant articles thereafter. Through this process, 2,157 abstracts were identified.

In the next step of abstract review and selection of articles, inclusion and exclusion criteria were applied. Articles were selected if they (1) were published between 2015 and June 15th 2019, (2) were in the English language, (3) were available in full-text, (4) included adult population (18 years of age or over), (5) included primary (or embedded) populations residing in India, China/Hong Kong/Taiwan, Canada, or the United States, (6) focused on an online intervention utilizing a digital device with downloadable software to deliver mental health care either (therapist-assisted or non-assisted) by phone or computer/tablet, and (7) aimed to understand how online interventions can reduce, treat, or manage symptoms of depression and/or anxiety. The exclusion criteria were pharmacological studies, incomplete studies, protocols, systematic reviews, literature reviews, thesis or discussion papers. Also, studies that used online mental health interventions as screening tools were excluded. Other forms of interventions, such verbal interventions delivered over cellular phone calls or video calls, were excluded. To keep the review process broad, we applied the criteria manually. Based on these selection criteria, 18 articles formed the sample for the full review and synthesis.

The review of selected articles entailed data extraction and synthesis of findings. The data was extracted and charted in excel sheets according to author names, year of publication, study location and setting, study population and size, intervention type, study design, duration of study, objectives, outcome measures, and relevant findings (See Appendix 1). In order to synthesize the findings, an inductive thematic analysis was undertaken. The results reported in each of the included study were read and re-read carefully to answer specific questions examined in this review. The relevant texts were extracted and coded for patterns and compared across studies using the constant comparison 
technique to identify themes and sub-themes and draw links wherever possible. The social determinants of health perspective was employed to enrich synthesis and interpretation (World Health Organization, 2010).

\section{RESULTS}

Out of 18 selected studies, 10 were identified as being a part of the global North (five Canadian and five US based) and there were eight studies identified as being a part of the global South (six in China and two in India). The most frequent study design was randomized controlled trial (7 studies) followed by cross-sectional survey (3 studies), non-randomized trials ( 2 studies), and other designs. Table 1 presents more descriptive details. The results are thematically summarized to answer the specific questions examined in the review. We present here each theme with dominant and unique findings pertinent to the global South and North.

\section{Effectiveness/Efficaciousness of MHApps}

Effectiveness in improving depressive and/or anxiety symptoms was a key focus for seven studies in the global North (Arean, 2016; Hadjistavropoulos et al., 2016a; Hadjistavropoulos et al., 2016b; Howells et al., 2016; Jones et al., 2016; Mohr et al., 2017; Pugh et al., 2016). All seven studies showed to have significantly improved depressive and/or anxiety symptoms amongst the study participants in some capacity. Participants who used a MHApp throughout the duration of these studies showed substantial reductions in primary outcome scores including, the Patient Health Questionnaire-9 (PHQ-9) scores, Generalized Anxiety Disorder-7 (GAD-7) scores, the Edinburgh Postnatal Depression Scale scores, and the Center for Epidemiologic Studies Depression (CESD) scale scores. Further research is needed with larger sample sizes as the results were not sub-analyzed by socioeconomic position or ethnicity (Arean et al., 2016; Hadjistavropoulos et al., 2016a; Hadjistavropoulos et al., 2016b; Howells et al., 2016; Mohr et al., 2017; Pugh et al., 2016).

Five of the ten studies in the global South, discussed the effectiveness of MHApps in improving depressive and/or anxiety symptoms (Auyeung and Mo, 2018; Hung et al., 2016; Kishimoto et al., 2016; Mak et al., 2015; Mak et al., 2017). All five of the studies were conducted in China and most of the studies showed significant improvement in depressive and/or anxiety symptoms. Two of the studies were with clinically diagnosed patients (Auyeung and Mo, 2018; Hung et al., 2016) and the other studies involved community samples (Kishimoto et al., 2016; Mak et al., 2015; Mak et al., 2017). In the first group of studies, the depression and anxiety scores improved post-intervention for participants on the CESD-short version scale, PHQ-9 and the Visual Analogue Scale for anxiety. For example, Auyeung and Mo's (2018) 6-day online positive-psychological intervention (PPI) indicated that PPI improved flourishing $(p<0.01)$ and reduced clinically diagnosed depressive symptoms $(p<0.05)$ compared to the control. All of these studies were moderate in size. In the second group of the studies, two studies revealed that the depression and anxiety scores improved post-intervention for participants on the Social Interaction Anxiety Scale and the 18-item Mental Health Inventory (Kishimoto et al., 2016; Mak et al., 2017). However, one study showed there was no significant time $x$ group interaction found on the short version of the Depression Anxiety Stress Scale (Mak et al., 2015).

\section{Impact of MHApps Access: Use, Uptake and Adherence}

Eight of the reviewed studies in the global North reported findings relevant to the use, uptake, and adherence to online MHApps (Abel et al., 2018; Pugh et al., 2016; Wang et al., 2016; Arean et al., 2016; Hadjistavropoulos et al., 2016a; Hadjistavropoulos et al., 2016b; Mohr et al., 2017; Pugh et al., 2016).

Two studies from the US reported variations in the use of MHApps by gender, age, race, income, education level and area of residence. The US-based study by Abel et al. (2018) involving veterans who had a mental health diagnosis (e.g., depression and anxiety) reports several statistically significant variations in the use across sub-groups. For instance, they found that low-income patients who could receive free care were significantly less likely to use online MHApps known as My HealtheVet and/or Clinical Video Telehealth than those who did not (Abel et al., 2018). They also found that Latin- and African Americans were less likely than White-Americans to use either of these tools, while women were more likely to use both than men (Abel et al., 2018). In terms of veterans in rural areas, they were less likely 
to adopt My HealtheVet compared with urban veterans but much more likely to engage with Clinical Video Telehealth or both tools (Abel et al., 2018). The study by Hadjistavropoulos et al. (2016a) reported that younger participants with minimal education, who were uncomfortable with written communication, were taking psychotropic medication, and were under psychiatric care, had fewer program starts or lower symptom improvement in one of the two online mental health programs.

Four of the US and Canada based studies reported on the adherence as a function of the delivery mode of MHApps (Arean et al., 2016; Hadjistavropoulos et al., 2016b; Mohr et al., 2017; Pugh et al., 2016). The findings of these studies suggest that online therapy works best in the presence of or through the guidance of a therapist. For example, the Pugh et al. study (2016) had a high degree of program adherence to their TA-ICBT program $(60 \%$ completed their program); this was most apparent when there were therapists guiding the program, such as through weekly telephone calls. Interestingly, one study observed no differences in completion rates whether therapists were registered providers, graduate students, or were trained in psychology or another discipline (Hadjistavropoulos et al., 2016b, p. 27). Arean et al. tested self-guided mobile apps without any therapist and with minimal staff contact for outcome assessments for depression. The results showed high dropout rates with nearly half of the enrolled participants not even downloading their assigned apps (2016, p. 9).

Five of the studies in the global South presented findings related to use, including dropout or adherence. Three studies (two in Hong Kong and one in mainland China) highlighted the promising efficacy of MHApps as a less costly and highly scalable approach for mental health compared to face-to-face therapy (Hung et al., 2016; Mak et al., 2015; Mak et al., 2017). Further, much like the global North, MHApps examined in Hong Kong and mainland China showed that standalone apps may not be enough to instill regular active use among users. Mak et al.'s 2017 study had high attrition rates throughout study duration (10.12\% completed the 3-month follow-up) and Hung et al.'s 2016 study showed a trend of decreased frequency of use in an 8-week period both of these studies used MApps without a therapist. However, Kishimoto et al.'s 2016 study showed the effects of a self-guided ICBT intervention were not different from the effects of a guided ICBT intervention in social anxiety. Hung et al.'s 2016 study of Chinese outpatients who had clinical depressive disorder found only limited smartphone use among participants ( $<500 \mathrm{mb}$ per month). However, higher use of the online intervention called iHOPE because it had offline capabilities (Hung et al., 2016, p. 134).

\section{Facilitators for MHApps}

In terms of the facilitators for MHAPPs' implementation or use, the review of studies led to identification of two sub-themes: the engagement of users, preferences, and personalization; and the quality of content.

\section{Engagement of users, preferences and personalization}

In five of the reviewed studies from the US and Canada, strategies for engagement of users, incorporation of their preferences, and personalization of MHApps were shown to facilitate the use of such interventions (Hadjistavropoulos et al., 2016a; Howells et al., 2016; Lipschitz et al., 2019; Mohr et al., 2017; Wang et al., 2016). User engagement for MHApps were greatest when applications were context-sensitive to the needs of the users by allowing for personalization of application choices. For instance, IntelliCare, for instance, had the highest app usage than other apps in its study with an average of 195 app launches per participant over the 8-week study, possibly attributable to the broad range of personalizing features which participants can choose from (Mohr et al., 2017). In addition, Lipschitz et al.'s 2019 study highlights participant interest in using apps that facilitate core functions of cognitive behavioral therapy such as cognitive restructuring and behavioral activation (70\% of participants with smart devices) and interest in features that would promote wellness in areas of behavioural health such as sleep difficulties and inactivity (73\% of all participants).

Likewise, in the global South, four studies highlighted the importance of user engagement, preferences, and personalization for MHAPPS though the preferred features were not the same as in the global North (Auyeung and Mo, 2018; Mak et al., 
2015; Patel et al., 2017). Across three studies, more participants seemed to have improved positive wellbeing when interactive elements (supplementary messages or flourishing impact) or Chinese-relevant themes (pressure for academic excellence, filial piety, and balancing school and social life) were incorporated (Auyeung and Mo, 2018, p. 12; Mak et al., 2015). Tewari et al.'s 2017 study in India also reveals the need to be contextually specific and use multiple ways to engage participants in online interventions. Interviews with community members indicated that the knowledge received through the intervention empowered them to approach Accredited Social Health Activists (ASHAs - lay health workers) and share their mental health symptoms (Tewari et al., 2017, p. 5).

\section{Quality of content}

A study based in the US by Howells et al. reported the content of the online mobile intervention matters. The benefits increase when content is evidence-based and includes empirically-based strategies such as expressing gratitude, performing acts of kindness, visualizing one's best possible self, using character strengths and practicing mindfulness (Howells et al. 2016, p. 175). Benefits also increased when user enjoyment was taken into consideration (Howells et al. 2016, p. 175). Likewise, a 2017 study in the global South by Patel al. showed that a panel of three physicians agreed that retaining $C B T$ and Behavioral Activation (BA) modules were essential for MHAPP use in China, whereas the panel was split on the use of Interpersonal Psychotherapy (p. 5), revealing their challenges regarding cultural relevance.

\section{Barriers for MHApps}

The review of included studies led to identification of barriers to the implementation or use of MHApps; these were unique for the global North and South. In a US based study, the level of awareness about MHApps was identified as a barrier among veterans (Lipschitz et al., 2019). The authors found that veterans in Boston reported their most frequent concerns related to using an app for mental illness included: a lack in proof of efficacy $(71.8 \%)$, data privacy (59.1\%), and in general not knowing where to find such an app that would help with their mental illness (51.0\%) (p. 4). Participants' ratings of interest in using an app recommended by a clinician were significantly greater than general-interest ratings and even greater when the recommending clinician was a specialty mental health provider (Lipschitz et al., 2019). The same study found that access to devices and use of apps, in general, was high - nearly $80 \%$ reported owning smart devices, and of those with smart devices, nearly $90 \%$ reported that they use apps in general. Interest in using mobile apps for mental illness was high at $70 \%$ of the sample; however, it was somewhat less than using mobile apps in general.

In the global South, a few studies reported logistical or implementational barriers. Practical barriers were identified by Nahar et al. (2017) by examining how realistic it is to use mHealth intervention for diabetes and depression in rural India; the depression-related findings are explored here. The findings suggest that individuals suffering from depression are among the least likely to turn to their mobile phones in the first place (Nahar et al., 2017 , p. 10). They also noted that habitual and easy take-up of mHealth applications by patients themselves was inhibited due to $1 \mathrm{G}$ or $2 \mathrm{G}$ basic phone products along with seasonally erratic electricitysupply or short battery life (Nahar et al., 2017). Other barriers discussed by Tewari et al (2017, p. 6-7, 11) were stigma and discrimination related to receiving treatment, financial livelihood, social constraints, and gaps in using technology-based applications/IVR messages. Another barrier was related to the selfhelp focus in MHApps which is antithetical to the collectivist cultural values in the global south. In the Nahar et al.'s study, respondents expressed a desire that MHApps' could be used to support the family as a whole (Nahar et al., 2017).

\section{DISCUSSION}

Our review advances scholarly understanding about the access to online mental health interventions with a focus on depression and/or anxiety. This is a timely effort given the global mental health impact of COVID-19. In 2018, the WHO emphasized the potential of digital technologies to advance the Sustainable Development Goals and improve the accessibility, quality, and affordability of health services in all countries (World Health Organization, 2018a). We selected literature from the US and Canada to represent the global North, and China, 
India, Hong Kong and Taiwan for the global South. The findings of the review reveal convergence and divergence of the themes identified for the global South and North and are discussed below with implications for policy, practice, and research.

A key cross-cutting theme of examined regions was the effectiveness and facilitative role of MHApps in accessing mental health care. In this context, a notable phenomenon is the better working of online therapy in the presence of or through the guidance of a therapist. However, more research would help to unpack the underlying mechanisms. Nevertheless, policymakers in the global North could consider the provision of therapist-assisted MHApps as a universal care program given they have more mental health professionals available. In contrast, the policymakers in the global South would need investments in training mental health professionals along with the MHApps. There are innovative models on the rise in the global South for the former, such as training of community-based workers to provide mental health support (Kohrt et al., 2018).

The inclusion of diverse communities in the design and testing of MHApps is an area that needs attention in both global North and South. Our review of the studies from the global North demonstrated unequal access by socioeconomic position, ethnicity, gender, age and geographic location while such sub-analysis was not available for all studies. At the same time, reviewed studies revealed that engagement of users and inclusion of their preferences and personalization lead to better use, adherence, and impact of MHApps in both global North and South. These findings emphasize the need to conduct future research with larger and diverse samples to understand and address the digital divide. Further, these findings speak to a need to integrate MHApps humanistically for promoting mental wellbeing and alleviating symptoms of common mood disorders like depression and anxiety. A humanistically driven approach would focus on creating systems for people, unlike a technically driven approach that would fit people into systems. In fact, previous research has shown that patients who are likely to somatise their mental illness symptoms have no problem reporting psychological symptoms when asked directly (Ahmad et al., 2018). This kind of direct asking and information sharing could be operationalized via digital tools given their ease of use and ability to operate in multiple languages. In fact, a 2016 study showed promising results for a digital diabetes prevention program used by underserved, lowincome Hispanic prediabetic patients (Fontil et al., 2016). There was high engagement and satisfaction with the digital diabetes prevention program despite lower digital literacy skills (Fontil et al., 2016). Research such as this highlights the potential of MHApps for common disorders in diverse regions, when adapted correctly. Yet, a bottom-up community engaged approach is vital to combat the private industry's push in promoting MHApps that are not contextualized to local realities.

It is worth noting that the persistence of stigma in both the global North and South makes it clear that mental health must become a priority on all global public health agendas. In fact, according to the WHO's world health report, mental health, in general, has not been a part of many countries' agendas globally, and governments must begin taking action (World Health Organization, 2018b). Currently, more than $40 \%$ of countries have no mental health policy and over $30 \%$ have no mental health services/programs (World Health Organization, 2018b). Around 25\% of countries have no mental health legislation (World Health Organization, 2018b). International bodies like the WHO and professional associations for mental health and primary care could bring several countries together and develop a national mandate requiring a bottom-up approach from private industries developing MHApps. Such a policy shift would allow for the development of culturally appropriate MHApps and faster uptake through knowledge translation.

The results of this review also identify regionspecific themes. For example, there is a focus in the global North on raising awareness amongst users about MHApps, whereas studies in the global South focus on user attrition or dropout when delivering MHApps, along with structural barriers impeding accessibility to MHApps, and the contentious nature of "self-help". Regional differences likely involve broader forces such as the growing global hold of neoliberal policies that emphasize limiting government spending and incentivising private industry including for health/social care needs. Scholars also suggest the differential impact of neoliberalism on the global South and North. Mills and Fernando contend that political systems 
determine the way mental health services are organised because political theories affect the way problems of the mind are conceptualised (Mills \& Fernando, 2014, p. 193). In the global South, a shift to individualize the responsibility of one's mental health may be a result of the neoliberal forces - such as the push of MHApps by private industry - which, in effect, reconfigure distress resulting from poor economic conditions to a symptom of mental illness or blame the victim (Mills \& Fernando, 2014). The introduction of MHApps may be premature in settings where economic conditions are suboptimal and structural barriers are vast because the conditions of daily living must be addressed first or simultaneously. Furthermore, issues concerning mental health cannot be considered independently from other areas of development, such as education, employment, emergency responses and human rights capacity building (World Health Organization, 2019).

Some of the regional differences noted in the review may also be explained by the differences in the notions of life priorities and mental health and wellbeing prevalent in the global North and global South. We identified several studies in the global South where participants wished for their MHApps to be (re)framed to meet their cultural preferences. For instance, Patel et al.'s 2017 study highlighted that students within mainland China wanted their MHApps to have Chinese-relevant themes. The responses from these students included more themes pertaining to academic excellence, filial piety, and balancing school and social life (Patel et al., 2017). These insights suggest that a simple adaptation of MHApps to local context may not suffice, and that attention to cultural values and beliefs is crucial. Narayan Gopalkrishnan's 2018 study claims there are many key considerations that should be incorporated when working with diverse cultures in mental health care including emotional expression, shame, power distance between patient and provider, collectivism, spirituality, and religion. Furthermore, understanding the nature of treatment-seeking amongst a cultural group, including experiences of racism and discrimination, is necessary. Thus, there are severe repercussions on individuals and communities if systems and processes are not in place to enable mental health providers to work effectively across cultures (Gopalkrishnan, 2018). MHApps could best achieve this by building research capacity in the global
South and North for such innovations in a communityengaged manner.

The findings also offer insights for developing a digital health response to the impact of COVID-19 on peoples' mental health. For example, countries in the global North could prioritize public awareness for the MHApps which are evidence-based, while countries in the global South could invest more in supporting the digital infrastructure and addressing structural barriers. Further, government bodies and civic organizations ought to be vigilant about the push from private industry to deploy MHApps rapidly. Such quick upscaling poses risks of neglecting diverse local contexts and cultures, which are at the core of the innovations' acceptance, uptake, usability, and sustainability.

The interpretation of the review findings should involve caution due to some of its limitations. Given the limited number of countries included in the reviews, the results may not apply to all countries in the global North or South. Some relevant studies might not have been captured within our specific review criteria (e.g., English language) and search by a single author; however, the application of inclusion and exclusion criteria to over 2000 abstracts manually offer confidence about the breadth of studies included/considered. Further, we employed multiple search strategies including Google search, specific journals for digital health and the reference lists of selected studies.

\section{CONCLUSION}

This scoping review examined the potential of online mental health interventions in supporting access to mental health care in the global North and global South, reveals that MHApps for depression and anxiety are efficacious in improving symptoms across the examined regions. However, there are barriers restricting access to care such as public awareness in the global North and logistical barriers in the global South that must be addressed. A broader policy level emphasis is needed to address the logistical capabilities and cultural sensitivity of MHApps before readily implementing MHApps in marginalized communities. Doing so necessitates establishing programs that would enable the co-construction of participant narratives on the ground in order to ensure the context relevancy of interventions and 
accessibility. Future MHAPP research should take a multi-pronged, bottom-up approach to develop humanistic systems of care where social context and living conditions are considered. The hope is that researchers replicate this study with various countries in the global North and South and include MHApps developed for other mental health conditions and other illnesses.

\section{REFERENCES}

Abel, E.A., Shimada, S.L., Wang, K., Ramsey, C., Skanderson, M., Erdos, J., Godleski, L., Houston, T.K., \& Brandt, C.A. (2018). Dual Use of a Patient Portal and Clinical Video Telehealth by Veterans with Mental Health Diagnoses: Retrospective, Cross-Sectional Analysis. Journal of Medical Internet Research, 20(11), e11350.

Ahmad, F., Maule, C., Wang, J., \& Fung, W.L.A. (2018). Symptoms and Experience of Depression Among Chinese Communities in the West: A Scoping Review. Harvard Review of Psychiatry, 26(6), 340-351.

Andersson, G., \& Cuijpers, P. (2009). Internet-based and other computerized psychological treatments for adult depression: a metaanalysis. Cognitive Behaviour Therapy, 38, 196-205.

Andrews, G., Cuijpers, P., Craske, M.G., McEvoy, P., \& Titov, N. (2010). Computer therapy for the anxiety and depressive disorders is effective, acceptable and practical health care: a metaanalysis. PLoS ONE, 5, e13196.

Arean, P.A., Hallgren, K.A., Jordan, J.T., Gazzaley, A., Atkins, D.C., Heagerty, P.J., \& Anguera, J.A. (2016). The Use and Effectiveness of Mobile Apps for Depression: Results from a Fully Remote Clinical Trial. Journal of Medical Internet Research, 18(12), e330.

Arjadi, R., Nauta, M.H., Chowdhary, N., \& Bockting, C.L.H. (2015). A systematic review of online interventions for mental health in low- and middle-income countries: A neglected field. Global Mental Health, 2, e12.

Arksey, H., \& O'Malley, L. (2005). Scoping studies: towards a methodological framework. International Journal of Social Research Methodology, 8(1), 19-32.

Auyeung, L., \& Mo, P.K.H. (2018). The Efficacy and Mechanism of Online Positive Psychological
Intervention (PPI) on Improving Well-Being Among Chinese University Students: A Pilot Study of the Best Possible Self (BPS) Intervention. Journal of Happiness Studies.

Braveman, P. (2014). What Are Health Disparities and Health Equity? We Need to Be Clear. Public Health Reports, 129(1), 5-8.

Brynjolfsson, E., Horton, J. J., Ozimek, A., Rock, D., Sharma, G., \& TuYe, H. Y. (2020). COVID-19 and remote work: An early look at US data (No. w27344). National Bureau of Economic Research.

Christensen, H. (2010). Increasing access and effectiveness: using the internet to deliver low intensity CBT. In Oxford Guide to Low Intensity CBT Intervention (ed. BennettLevy, J., Richards, D. A., Farrand, P., Christensen, H., Griffiths, K.M., Kavanagh, D.J., Klein, B., Lau, M.A., Proudfoot, J., Ritterband, L., White, J., \& Williams, C.), pp. 53-68. Oxford University Press: Oxford.

Dados, N., \& Connell, R. (2012). The global south. Contexts, 11(1), 12-13.

Donker, T., van Straten, A., Riper, H., Marks, I., Andersson, G., \& Cuijpers, P. (2009). Implementation of internet-based preventive interventions for depression and anxiety: role of

support? The design of a randomized controlled trial. Trials, 10, 59.

Fairburn, C.G., \& Patel, V. (2017). The impact of digital technology on psychological treatments and their dissemination. Behavioral Research Therapy, 88, 19-25.

Fontil, V., McDermott, K., Tieu, L., Rios, C., Gibson, E., Sweet, C. C., Payne, M., \& Lyles, C. R. (2016). Adaptation and Feasibility Study of a Digital Health Program to Prevent Diabetes among Low-Income Patients: Results from a Partnership between a Digital Health Company and an Academic Research Team. Journal of Diabetes Research, 2016, 8472391.

Gopalkrishnan N. (2018). Cultural diversity and mental health: Considerations for policy and practice. Front Public Health, 6, 179.

Hadjistavropoulos, H.D., Pugh, N.E., Hesser, H., \& Andersson, G. (2016a). Predicting Response to Therapist-Assisted Internet-Delivered Cognitive Behavior Therapy for Depression 
or Anxiety Within an Open Dissemination Trial. Behavior Therapy, 47(2), 155-165.

Hadjistavropoulos, H.D., Nugent, M.M., Alberts, N.M., Staples, L., Dear, B.F., \& Titov, N. (2016b). Transdiagnostic Internet-delivered cognitive behaviour therapy in Canada: An open trial comparing results of a specialized online clinic and nonspecialized community clinics. Journal of Anxiety Disorders, 42, 19-29.

Howells, A., Ivtzan, I., \& Eiroa-Orosa, F.J. (2016). Putting the 'app' in Happiness: A Randomised Controlled Trial of a Smartphone-Based Mindfulness Intervention to Enhance Wellbeing. Journal of Happiness Studies, 17(1), 163-185.

Hung, S., Li, M., Chen, Y., Chiang, J., Chen, Y., \& Hung, G.C. (2016). Smartphone-Based Ecological Momentary Assessment for Chinese Patients with Depression: An Exploratory Study in Taiwan. Asian Journal of Psychiatry, 23, 131136.

Jones, S.L., Hadjistavropoulos, H.D., \& Soucy, J.N. (2016). A randomized controlled trial of guided internet-delivered cognitive behaviour therapy for older adults with generalized anxiety. Journal of Anxiety Disorders, 37, 1-9.

Kincheloe, J., \& McLaren, P. (2005). Rethinking critical theory and qualitative research in Denzin, $\mathrm{N}$. K., \& Lincoln, Y. S. (eds). The Sage handbook of qualitative research, Sage Publications Ltd, Thousand Oaks, CA, 303-342.

Kishimoto, T., Krieger, T., Berger, T., Qian, M., Chen, H., \& Yang, Y. (2016). Internet-Based Cognitive Behavioral Therapy for Social Anxiety with and without Guidance Compared to a Wait List in China: A Propensity Score Study, Psychotherapy Psychosomatic, 85, 317-319.

Kohrt, B. A., Asher, L., Bhardwaj, A., Fazel, M., Jordans, M., Mutamba, B. B., Nadkarni, A., Pedersen, G. A., Singla, D. R., \& Patel, V. (2018). The Role of Communities in Mental Health Care in Low- and Middle-Income Countries: A Meta-Review of Components and Competencies. International Journal of Environmental Research and Public Health, 15(6), 1279.

Lipschitz, J., Miller, C.J., Hogan, T.P., Burdick, K.E., Lippin-Foster, R., Simon, S.R., \& Burgess, J. (2019). Adoption of Mobile Apps for
Depression and Anxiety: Cross-Sectional Survey Study on Patient Interest and Barriers to Engagement. JMIR Mental Health, 6(1), e11334.

Mak, W.W.S., Chan, A.T.Y., Cheung, E.Y.L., Lin, C.L.Y., \& Ngai, K.C.S. (2015). Enhancing Web-based mindfulness training for mental health promotion with the health action process approach: randomized controlled trial. Journal of Medical Internet Research, 17(1), e8.

Mak, W.W., Chio, F.H., Chan, A.T., Lui, W.W., \& Wu, E.K. (2017). The Efficacy of Internet-Based Mindfulness Training and CognitiveBehavioral Training with Telephone Support in the Enhancement of Mental Health Among College Students and Young Working Adults: Randomized Controlled Trial. Journal of Medical Internet Research, 19(3), e84.

Mathers, C.D., \& Loncar, D. (2006). Projections of global mortality and burden of disease from 2002 to 2030. Plos Med, 3(11), e442.

Mills, C., \& Fernando, S. (2014). Globalising Mental Health or Pathologising the Global South? Mapping the Ethics, Theory and Practice of Global Mental Health. Disability and the Global South, 1(2), 188-202.

Mohr, D.C., Tomasino, K.N., Lattie, E.G., Palac, H.L., Kwasny, M.J., Weingardt, K., Karr, C.J., Kaiser, S.M., Rossom, R.C., Bardsley, L.R., Caccamo, L., Stiles-Shields, C., \& Schueller, S.M. (2017). IntelliCare: An Eclectic, SkillsBased App Suite for the Treatment of Depression and Anxiety. Journal of Medical Internet Research, 19(1), e10.

Nahar, P., Kannuri, N.K., Mikkilineni, S., Murthy, G.V.S., \& Phillimore, P. (2017). mHealth and the management of chronic conditions in rural areas: a note of caution from southern India. Anthropology \& Medicine, 24(1), 1-16.

Naslund, J. A., Aschbrenner, K. A., Araya, R., Marsch, L. A., Unützer, J., Patel, V., \& Bartels, S. J. (2017). Digital technology for treating and preventing mental disorders in low-income and middle-income countries: a narrative review of the literature. The Lancet. Psychiatry, 4(6), 486-500.

Patel, U., Sobowale, K., Fan, J., Liu, N., Kuwabara, S., Lei, Z., Sherer, R., \& Van Voorhees, B. (2017). Cultural considerations for the adaptation of an Internet-based intervention for 
depression prevention in Mainland China. International Journal of Adolescent Medicine and Health, 29(5), 1.

Poushter, J. (2016). Smartphone Ownership and Internet Usage Continues to Climb in Emerging Economies. Pew Research Center.

Poushter, J., Bishop, C., \& Chwe, H. (2018). Social media use continues to rise in developing countries, but plateaus across developed ones, Washington: Pew Internet and American Life Project, available at: http://www.pewglobal.org/wpcontent/uploads/sites/2/2018/06/PewResearch-Center_Global-Tech-Social-MediaUse_2018.06.19.pdf (accessed 8 July 2019).

Pugh, N.E., Hadjistavropoulos, H.D., \& Dirkse, D. (2016). A Randomised Controlled Trial of Therapist-Assisted, Internet-Delivered Cognitive Behavior Therapy for Women with Maternal Depression. PloS One, 11(3), e0149186.

Rathod, S., Pinninti, N., Irfan, M., Gorczynski, P., Rathod, P., Gega, L., \& Naeem, F. (2017). Mental Health Service Provision in Low- and Middle-Income Countries. Health Services Insights, 2017(10), e1178632917694350.

Ritchie, H., \& Roser, M. (2019). "Mental Health”, Our World in Data, available at: https://ourworldindata.org/mental-health (accessed 10 July 2019).

Salari, N., Hosseinian-Far, A., Jalali, R., Vaisi-Raygani, A., Rasoulpoor, S., Mohammadi, M., Rasoulpoor, S., \& Khaledi-Paveh, B. (2020). Prevalence of stress, anxiety, depression among the general population during the COVID-19 pandemic: a systematic review and meta-analysis. Globalization and Health, 16(1), 57.

Tewari, A., Kallakuri, S., Devarapalli, S., Jha, V., Patel, A., \& Maulik, P.K. (2017). Process evaluation of the systematic medical appraisal, referral and treatment (SMART) mental health project in rural India. BMC Psychiatry, 17(1), 385.

The World Bank. (2019). "GDP", The World Bank, available at: https://data.worldbank.org/indicator/NY.G DP.MKTP.CD?most_recent_value_desc=true

Wang, J., Lam, R.W., Ho, K., Attridge, M., Lashewicz, B.M., Patten, S.B., Marchand, A., Aiken, A., Schmitz, N., Gundu, S., Rewari, N., Hodgins,
D., Bulloch, A., \& Merali, Z. (2016). Preferred Features of E-Mental Health Programs for Prevention of Major Depression in Male Workers: Results from a Canadian National Survey. Journal of Medical Internet Research, 18(6), e132.

Wang, P. S., Aguilar-Gaxiola, S., Alonso, J., Angermeyer, M. C., Borges, G., Bromet, E. J., Bruffaerts, R., de Girolamo, G., de Graaf, R., Gureje, O., Haro, J. M., Karam, E. G., Kessler, R. C., Kovess, V., Lane, M. C., Lee, S., Levinson, D., Ono, Y., Petukhova, M., Posada-Villa, J., \& Wells, J. E. (2007). Use of mental health services for anxiety, mood, and substance disorders in 17 countries in the WHO world mental health surveys. Lancet (London, England), 370(9590), 841850.

Worldometers. (2019). "India Population", Worldometers, available at: https://www.worldometers.info/worldpopulation/india-population (accessed 8 July 2019).

World Health Organization. (2010). A conceptual framework for action on the social determinants of health: debates, policy \& practice, case studies, World Health Organization, available at: http://apps.who.int/iris/bitstream/10665/4 4489/1/9789241500852_eng.pdf (accessed 10 July 2019).

World Health Organization. (2020). Depression. World Health Organization, available at: https://www.who.int/news-room/factsheets/detail/depression

World Health Organization India. (2019). Mental health in India, World Health Organization, available at: http://www.searo.who.int/india/topics/me ntal_health/about_mentalhealth/en/ (accessed 10 July 2019).

World Health Organization. (2019). Mental health, poverty and development, https://www.who.int/mental_health/policy /development/en/ (2019, accessed 24 November 2019).

World Health Organization. (2018a). WHA71.7, Agenda item 12.4, Digital Health, https://apps.who.int/gb/ebwha/pdf_files/ WHA71/A71_R7-en.pdf/ (accessed 24 November 2019). 
International Health Trends and Perspectives

World Health Organization. (2013). WHO Mental Health Action Plan 2013-2020, World Health Organization, available at: https://apps.who.int/iris/bitstream/handle/ 10665/89966/9789241506021_eng.pdf;jses sionid=B91B49C31683C1A2B75AD1999812 AF5F?sequence $=1$ (accessed 10 July 2019).

World Health Organization. (2018b). World health report, World Health Organization, available at:

https://www.who.int/whr/2001/media_cen tre/press_release/en/ (accessed 10 July 2019). 
Figure 1: Search Flow

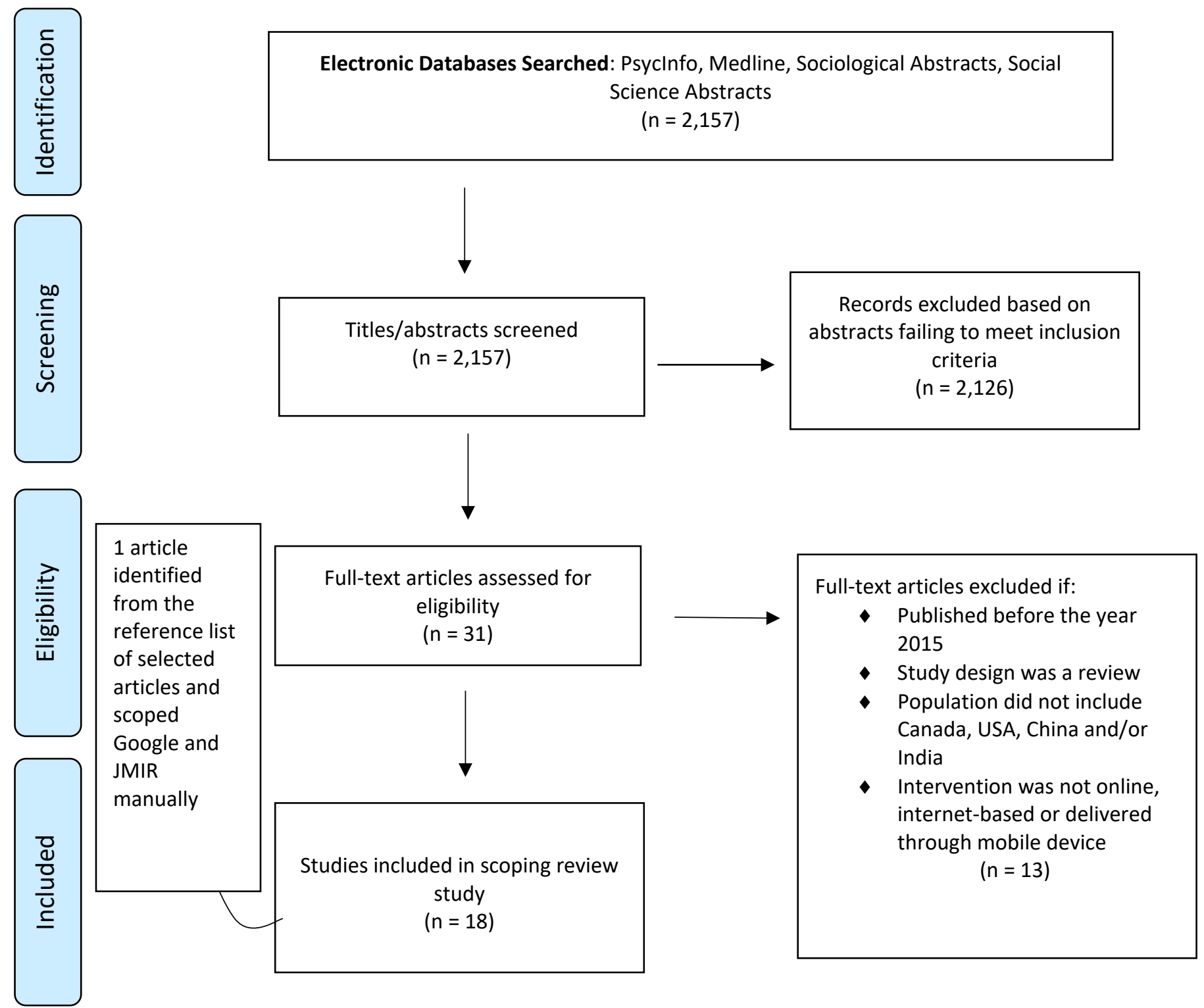


Table 1. Selected Studies for Review

\begin{tabular}{|c|c|c|c|}
\hline $1^{\text {st }}$ Author $\&$ Year & Location & Design & Sample \\
\hline Abel EA, 2018 & $\begin{array}{l}\text { United States, } \\
\text { Bedford }\end{array}$ & $\begin{array}{l}\text { Medical chart } \\
\text { review }\end{array}$ & $N=2,171,325 ;$ veterans \\
\hline Arean PA, 2016 & $\begin{array}{l}\text { United States } \\
\text { (all } 50 \text { states) }\end{array}$ & $\mathrm{RCT}$ & $\begin{array}{l}\mathrm{N}=626 ; T_{x}^{1}(n=211), T_{x}^{2}(n=209) \\
\text { control }(n=206) ; \text { mild to mod depression }\end{array}$ \\
\hline $\begin{array}{l}\text { Auyeung L \& Mo PKH, } \\
2018\end{array}$ & $\begin{array}{c}\text { China, } \\
\text { Hong Kong }\end{array}$ & RCT & $\begin{array}{l}N=100 ; T_{x}(n=48), \text { control }(n=52) \\
\text { university students }\end{array}$ \\
\hline Hadjistavropoulos HD, 2016a & $\begin{array}{c}\text { Canada, } \\
\text { Saskatchewan }\end{array}$ & Exploratory & $\begin{array}{c}\mathrm{N}=195 ; T_{x}^{1}(n=83) \text { compared to } T_{x}{ }^{2}(n=112) ; \\
\text { report mild } S_{x} \text { of depression/anxiety }\end{array}$ \\
\hline Hadjistavropoulos HD, 2016b & $\begin{array}{l}\text { Canada, } \\
\text { Saskatchewan }\end{array}$ & $\begin{array}{l}\text { Uncontrol, } \\
\text { open trial }\end{array}$ & $\begin{array}{l}\mathrm{N}=338 \text { upon completion; exhibiting lower } \\
\text { intensity depression or anxiety }\end{array}$ \\
\hline Howells A, 2016 & $\begin{array}{l}11 \text { countries, } \\
\text { includes USA }\end{array}$ & $\mathrm{RCT}$ & $\begin{array}{l}N=121 ; T_{x}(n=57), \text { control }(n=64) \\
\text { general public with smartphone }\end{array}$ \\
\hline Hung S, 2016 & $\begin{array}{l}\text { China, } \\
\text { Taiwan }\end{array}$ & $\begin{array}{l}\text { Exploratory } \\
\text { (EMA) }\end{array}$ & $\begin{array}{c}\mathrm{N}=54 \text { active users; } \\
\text { Chinese outpatients } \mathrm{dx} \text { with depression }\end{array}$ \\
\hline Jones SL, 2016 & $\begin{array}{c}\text { Canada, } \\
\text { Saskatchewan }\end{array}$ & RCT & $\begin{array}{l}N=46 ; T_{x}(n=24) \text {, control }(n=22) ; \\
\text { older adults ( } \geq 60 \text { years old) } d x \text { with GAD }\end{array}$ \\
\hline Kishimoto T, 2016 & $\begin{array}{l}\text { China } \\
\text { (online) }\end{array}$ & $\begin{array}{l}\text { Propensity } \\
\text { score study }\end{array}$ & $\begin{array}{c}N=197 ; T_{x}^{1}(n=63), T_{x}^{2}(n=93), \\
\text { control }(n=41) ; \text { Chinese adults exhibiting SAD }\end{array}$ \\
\hline Lipschitz J, 2019 & $\begin{array}{l}\text { United States, } \\
\text { Boston }\end{array}$ & Survey & $\mathrm{N}=149 ;$ veterans \\
\hline Mak WWS, 2015 & $\begin{array}{c}\text { China, } \\
\text { Hong Kong }\end{array}$ & RCT & $\begin{array}{c}N=321 ; T_{x}^{1}(n=105), T_{x}^{2}(n=104), \\
\text { control }(n=79) ; \text { university members }\end{array}$ \\
\hline Mak WWS, 2017 & $\begin{array}{l}\text { China, } \\
\text { Hong Kong }\end{array}$ & $\mathrm{RCT}$ & $\begin{array}{l}\mathrm{N}=127 \text { completed } 3 \text {-month follow-up; } \\
\text { college students and working adults }\end{array}$ \\
\hline Mohr DC, 2017 & $\begin{array}{l}\text { United States, } \\
\text { Minnesota }\end{array}$ & $\begin{array}{l}\text { Single-arm } \\
\text { pilot trial }\end{array}$ & $\begin{array}{l}\mathrm{N}=99 ; \text { patients with elevated } \\
\mathrm{S}_{\mathrm{x}} \text { of depression/ anxiety }\end{array}$ \\
\hline
\end{tabular}




\begin{tabular}{|c|c|c|c|}
\hline Nahar P, 2017 & $\begin{array}{c}\text { India, } \\
\text { Andhra Pradesh }\end{array}$ & $\begin{array}{l}\text { Qualitative } \\
\text { interviews }\end{array}$ & $\begin{array}{c}\mathrm{N}=21 \text { (13 men, } 8 \text { women); diabetics who } \\
\text { travelled to either of two clinics }\end{array}$ \\
\hline Patel U, 2017 & $\begin{array}{l}\text { China, } \\
\text { Wuhan }\end{array}$ & Survey & $\begin{array}{c}\mathrm{N}=20 \text { students } \& \mathrm{~N}=3 \\
\text { psychiatrists; medical school }\end{array}$ \\
\hline Pugh NE, 2016 & $\begin{array}{c}\text { Canada, } \\
\text { Saskatchewan }\end{array}$ & RCT & $\begin{array}{l}\mathrm{N}=50 ; 25 \text { per study arm; } \\
\text { women dx with maternal depression }\end{array}$ \\
\hline Tewari A, 2017 & $\begin{array}{c}\text { India, } \\
\text { West Godavari }\end{array}$ & $\begin{array}{l}\text { Mixed } \\
\text { methods }\end{array}$ & $\begin{array}{l}\mathrm{N}=30 \text { villages; exclusion any } \\
\text { severe physical disorder that limits access }\end{array}$ \\
\hline Wang J, 2016 & $\begin{array}{c}\text { Canada, } \\
10 \text { Provinces }\end{array}$ & Survey & $\begin{array}{c}\mathrm{N}=841 ; \text { working men at high }(\mathrm{n}=511) \\
\text { \& low }(\mathrm{n}=330) \text { depression risk }\end{array}$ \\
\hline
\end{tabular}

Abbreviations: dx - Diagnosed, EMA - Ecological Momentary Assessment, GAD - Generalized Anxiety Disorder, mod - moderate, RCT - Randomized Control Trial, SAD - Social Anxiety Disorder, Sx - Symptoms, Tx - treatment group, Tx1 - Treatment group 1, Tx2 - Treatment group 2 